\title{
Effect of sodium ascorbate on the bond strength of silorane and methacrylate composites after vital bleaching
}

Eda Güler(a)

Nihan Gönülol(a)

Özgün Yusuf Özyilmaz(b)

Ali Çağin Yücel(c)

(a) Department of Restorative Dentistry, Faculty of Dentistry, Ondokuz Mayis University, Samsun, Turkey.

(b) Department of Prosthodontic Dentistry, Faculty of Dentistry, Selçuk University, Konya, Turkey.

(c) Department of Endodontics, Faculty of Dentistry, Ondokuz Mayis University, Samsun, Turkey.
Declaration of Interests: The authors certify that they have no commercial or associative interest that represents a conflict of interest in connection with the manuscript.

Corresponding Author:

Eda Güler

E-mail: edaguler@omu.edu.tr

Submitted: Feb 11, 2013

Accepted for publication: May 08, 2013

Last revision: May 23, 2013
Abstract: We investigated the effect of sodium ascorbate (SA) on the microtensile bond strengths (MTBSs) of different composites to bovine enamel after vital bleaching with hydrogen peroxide (HP) or carbamide peroxide $(\mathrm{CP})$. Thirty bovine incisors were randomly divided into five groups and treated with no bleaching application (control), 35\% HP alone, $35 \% \mathrm{HP}+10 \% \mathrm{SA}$ for 10 minutes (HP+SA), $16 \% \mathrm{CP}$ alone, or $16 \% \mathrm{CP}+10 \% \mathrm{SA}$ for 10 minutes $(\mathrm{CP}+\mathrm{SA})$. Specimens were restored with Silorane adhesive and Filtek Silorane composite (designated as S/group) or with Clearfil SE bond and Filtek Supreme XT (designated as F/group). Composite build-up was created on the enamel. Sectioned specimens ( $n=10$ per group; $1 \mathrm{~mm}^{2}$ cross-sectional area) were created and stressed in a universal testing machine at $1 \mathrm{~mm} / \mathrm{min}$ crosshead speed. The application of $10 \%$ SA immediately after bleaching with $16 \%$ CP or $35 \%$ HP increased the enamel MTBS, regardless of the adhesive/ composite resin used. The resulting MTBS values were similar to those of the control groups. Use of $16 \% \mathrm{CP}$ and $35 \% \mathrm{HP}$ alone decreased the enamel MTBS, regardless of the adhesive/composite resin used, with $\mathrm{F} / \mathrm{CP}+\mathrm{SA}=\mathrm{F} / \mathrm{HP}+\mathrm{SA}=\mathrm{F} / \mathrm{CP}=\mathrm{S} / \mathrm{CP}+\mathrm{SA}=\mathrm{S} / \mathrm{HP}+\mathrm{SA}=\mathrm{S} / \mathrm{C}>\mathrm{S} / \mathrm{CP}=$ $\mathrm{S} / \mathrm{HP}=\mathrm{F} / \mathrm{CP}=\mathrm{F} / \mathrm{HP}(p<0.05)$. We concluded that the application of SA for 10 minutes immediately after vital bleaching increases the enamel BS for dimethacrylate- and silorane-based composites.

Descriptors: Dental Restoration Failure; Dental Debonding; Composite Resins.

\section{Introduction}

Whereas extrinsic tooth discoloration can be removed by prophylactic cleaning procedures, intrinsic tooth staining requires chemical bleaching. ${ }^{1}$ Vital tooth bleaching is a widespread procedure for which several techniques and materials have been developed ${ }^{2}$ (e.g., in-office or power bleaching, dentist-controlled home bleaching, and market bleaching products). ${ }^{3}$ This treatment causes porosity and an over-etched appearance along with loss of prismatic enamel structure, calcium loss and changes in the organic component of enamel. Furthermore, bleaching treatments adversely affect the bond strength (BS) of composite to enamel when bonding is immediately performed after bleaching. ${ }^{4}$ This decreased BS has been related to the presence of residual hydrogen peroxide (HP) in the interprismatic spaces, ${ }^{5,6}$ which can prevent adequate infiltration 
of the bonding agent into the dental structures and inhibit its polymerization. ${ }^{7}$

The use of antioxidant agents after bleaching has been suggested to avoid compromising BS. ${ }^{8-10}$ Biocompatible reducing agents, such as ascorbic acid and its salts, neutralize residual free radicals and decrease various oxidative compounds. ${ }^{11}$ If antioxidant treatment of bleached enamel before bonding can reverse the reduced BS of composite resin, then this approach could be used as an alternative to delaying the restorative procedure after bleaching. ${ }^{12}$

A resin system was recently developed that is based on the ring-opening polymerization of silorane molecules containing both siloxane and oxirane, rather than the free radical polymerization of dimethacrylate (DMA) monomers. However, the influence of bleaching on the BS of silorane-based materials to the bleached substrate is unclear. ${ }^{13}$ Several studies have evaluated the effects of bleaching on the BS of composite resins, indicating that siloraneand DMA-based resin systems may exhibit similar BS values. ${ }^{13,14}$

We performed a study to investigate the neutralizing effect of $10 \%$ sodium ascorbate (SA) solution on the microtensile BS (MTBS) of silorane-based and DMA-based composite resins to enamel after bleaching with different vital bleaching procedures. The hypothesis tested was that SA would affect the MTBS of both composite types with different monomer structures after vital bleaching.

\section{Methodology}

Thirty bovine incisors were used in this study. The tooth surfaces were cleaned via scaling to remove any soft tissue. Crowns were separated from the roots $1 \mathrm{~mm}$ apically to the cementoenamel junction using a diamond saw under water cooling. Enamel surfaces were obtained by trimming the labial surfaces of the crown section to create standard enamel slabs $(8 \times 8 \mathrm{~mm})$. The slab surfaces were flattened using aluminum oxide abrasive papers (300600 grit) under water irrigation. All enamel surfaces were examined with a stereomicroscope (Nikon SMZ 1500, Tokyo, Japan). Any specimens with cracks or defects were excluded. The slabs were randomly divided into five groups and treated with no bleaching (group C, control), 35\% HP (group HP), $35 \%$ HP followed by $10 \%$ SA for 10 minutes (group $\mathrm{HP}+\mathrm{SA}), 16 \%$ carbamide peroxide (CP; group $\mathrm{CP}$ ), or $16 \% \mathrm{CP}$ followed by $10 \% \mathrm{SA}$ for 10 minutes (group $\mathrm{CP}+\mathrm{SA}$ ).

\section{Bleaching procedures}

In groups $\mathrm{HP}$ and $\mathrm{HP}+\mathrm{SA}$, an office-bleaching solution of 35\% HP (H35 Total Blanc Office; Nova DFL, Rio de Janeiro, Brazil) was applied to the enamel surfaces for 30 minutes twice a day (at 9 am and $5 \mathrm{pm})$ at 3-day intervals. The effectiveness was increased by stirring the gel every 5 minutes. In groups $\mathrm{CP}$ and $\mathrm{CP}+\mathrm{SA}$, a home-bleaching solution of $16 \%$ CP gel (Zaris White \& Brite; 3M ESPE, St. Paul, USA) was applied to the enamel surfaces for 8 hours per day for 7 days, according to the manufacturer's instructions.

The samples were stored in artificial saliva (1.160 $\mathrm{g} / \mathrm{L} \mathrm{NaCl}, 0.600 \mathrm{~g} / \mathrm{L} \mathrm{CaCl}_{2}, 0.600 \mathrm{~g} / \mathrm{L} \mathrm{KH}_{2} \mathrm{PO}_{4}$, 1,491 g/L KCl, $0.050 \mathrm{~g} / \mathrm{L} \mathrm{NaF}$, and $100 \mathrm{~mL}$ distilled ionized water). In the groups $\mathrm{HP}+\mathrm{SA}$ and $\mathrm{CP}+\mathrm{SA}$, the surfaces were treated with $10 \% \mathrm{SA}$ for 10 minutes after the bleaching procedures. To prepare the solution, 10\% SA (ascorbic acid sodium salt) was prepared by a method in which $98 \%$ SA was dissolved in purified water by mixing at room temperature ( $\mathrm{pH}$ 7.5). Specimens were rinsed with distilled water and dried with compressed air.

\section{Bonding procedures}

The samples were divided into two subgroups. In the first subgroup (designated as S/group), Silorane Adhesive System (3M ESPE) was applied to the flattened enamel surfaces. Primer was applied to the surface, which was scrubbed for 15 seconds, dried under a gentle stream of air, and cured for $10 \mathrm{sec}-$ onds with an LED light-curing unit (LCU; Hilux LEDMAX; Benlioğlu Dental Co., Ankara, Turkey) at $500 \mathrm{~mW} / \mathrm{cm}^{2}$. The bond was applied to the surface, gently air dried, and cured for 10 seconds with the same LCU. Filtek Silorane (3M ESPE) was used for a composite buildup ( $3 \mathrm{~mm}$ high) on the enamel surfaces, in two increments. Each increment was cured for 40 seconds using the same LCU.

In the second subgroup (designated as F/group), 
Table 1 - Materials used in this study.

\begin{tabular}{|c|c|c|c|}
\hline Product & Composition & Manufacturer & LOT Number \\
\hline Clearfil SE Bond & $\begin{array}{l}\text { Primer: MDP, HEMA, hydrophilic aliphatic dimethacrylate, di- } \\
\text { camphorquinone, N,N-diethanol p-toluidine, water } \\
\text { Bond: MDP, bis-GMA, HEMA, hydrophobic aliphatic dimethacrylate, } \\
\text { di-camphorquinone, N,N-diethanol p-toluidine, colloidal silica }\end{array}$ & $\begin{array}{l}\text { Kuraray, Okayama, } \\
\text { JAPAN }\end{array}$ & $01034 \mathrm{~A}$ \\
\hline $\begin{array}{l}\text { Filtek Silorane } \\
\text { Adhesive System }\end{array}$ & $\begin{array}{l}\text { Primer: HEMA, bis-GMA, water, ethanol, phosphoric acid } \\
\text { methacryloxyhexylesters, silane treated silica, copolymer of acrylic and } \\
\text { itaconic acid, ethyl methacrylate, 1,6 hexanediol dimethacrylate di- } \\
\text { camphorquinone, } \\
\text { Bond: substituted dimethacrylate, silane treated silica, TEGDMA, } \\
\text { phosphoric acid methacryloxyhexylesters, di-camphorquinone, 1,6 } \\
\text { hexanediol dimethacrylate }\end{array}$ & 3M ESPE, St. Paul, USA & 180901 \\
\hline Filtek Silorane & $0.47 \mu \mathrm{m}$ quartz-yttrium fluoride, siloranes & 3M ESPE, St. Paul, USA & 321126 \\
\hline Filtek Supreme XT & zirconia/silica, bis-GMA, UDMA, TEGDMA, bis-EMA & 3M ESPE, St. Paul, USA & 3910A2D \\
\hline Zaris White \& Brite & $16 \%$ carbamide peroxide & 3M ESPE, St. Paul, USA & 12424 \\
\hline $\begin{array}{l}\text { H35 Total Blanc } \\
\text { Office }\end{array}$ & $35 \%$ hydrogen peroxide & $\begin{array}{l}\text { Nova DFL, Rio de } \\
\text { Janeiro, Brazil }\end{array}$ & 11101552 \\
\hline
\end{tabular}

the Clearfil SE bond (Kuraray, Okayama, Japan) two-step self-etch adhesive system was applied to the enamel surfaces without acid etching. Primer was applied to the surface for 20 seconds and dried under a stream of air. The bond was applied, gently air dried, and cured for 10 seconds using the same LCU. Filtek Supreme XT (3M ESPE) was used for composite buildup $(\sim 3 \mathrm{~mm})$ in two increments and cured for 20 seconds using the same LCU. The materials used in this study are listed in Table 1.

\section{MTBS testing}

Prepared specimens were stored in distilled water at $37^{\circ} \mathrm{C}$ for 24 hours prior to MTBS testing. Specimens were mounted on acrylic resin blocks, sectioned into serial slabs, and sectioned into sticks $\left(\sim 1 \mathrm{~mm}^{2}\right.$ cross-sectional area). An average of 10 sticks was obtained for each group. Each stick was attached to a movable jig that was affixed to the MTBS tester with cyanoacrylate adhesive. The specimens were stressed in a universal testing machine (Bisco, Schaumburg, USA) at a crosshead speed of $1 \mathrm{~mm} / \mathrm{min}$. The load at failure (in N) was recorded, and the BS (in MPa) was calculated. Failure modes were evaluated by a single operator with a stereomicroscope at $80 \times$ magnification. Failure modes were classified as adhesive (between the adhesive and enamel), cohesive within the substrate (enamel or composite resins), or mixed (adhesive and cohesive fractures occurred simultaneously).

\section{Statistical analysis}

The Shapiro-Wilk normality test indicated normal data distributions for all groups $(p>0.05)$. Two-way analyses of variance (ANOVA) were performed with the SPSS for Windows statistical software (version 12.0.1; SPSS Inc., Chicago, USA) to evaluate the BS values between restorative materials and bleached enamel. Means were compared by the Dunnet test $(\alpha<0.05)$. The pretesting failures were not included in the statistical analyses.

\section{Results}

The MTBS values were significantly different by two-way ANOVA $(p<0.01)$. Table 2 displays the mean BS values, standard deviations, and group differences for all groups. No differences were detected between the composite groups $(p=0.397)$. The SA treatment caused differences between the groups $(p<0.01)$. Significant interactions were found between the composite and SA-treated groups $(p=0.017)$.

No differences $(p=0.291)$ in BS values were observed between the groups S/CP (7.6 MPa), S/HP (9.4 MPa), F/CP (9.8 MPa), and F/HP (9.9 MPa). Similarly, no differences $(p=0.070)$ in BS values 
Table 2 - Mean bond strengths (MPa), standard deviation and group differences.

\begin{tabular}{c|c|c|c|c}
\hline Composite & Treatment & Interactions & $\mathrm{n}$ & Mean (MPa) \pm SD \\
\hline \multirow{4}{*}{$\begin{array}{c}\text { Filtek } \\
\text { Silorane }\end{array}$} & $\mathrm{Control}$ & $\mathrm{S} / \mathrm{C}$ & 10 & $16.4 \pm 3.68^{\mathrm{b}}$ \\
\cline { 2 - 5 } & $\mathrm{HP}$ & $\mathrm{S} / \mathrm{HP}$ & 10 & $9.4 \pm 0.92^{\circ}$ \\
\cline { 2 - 5 } & $\mathrm{CP}$ & $\mathrm{S} / \mathrm{CP}$ & 10 & $7.6 \pm 1.54^{\mathrm{a}}$ \\
\cline { 2 - 5 } & $\mathrm{HP}+\mathrm{SA}$ & $\mathrm{S} / \mathrm{HP}+\mathrm{SA}$ & 10 & $15.0 \pm 1.39^{\mathrm{b}}$ \\
\cline { 2 - 5 } & $\mathrm{CP}+\mathrm{SA}$ & $\mathrm{S} / \mathrm{CP}+\mathrm{SA}$ & 10 & $15.0 \pm 2.79^{\mathrm{b}}$ \\
\hline \multirow{4}{*}{$\begin{array}{c}\text { Filtek } \\
\text { XT } \\
\text { XT }\end{array}$} & $\mathrm{Control}$ & $\mathrm{F} / \mathrm{C}$ & 10 & $14.9 \pm 1.13^{\mathrm{b}}$ \\
\cline { 2 - 5 } & $\mathrm{HP}$ & $\mathrm{F} / \mathrm{HP}$ & 10 & $9.9 \pm 0.96^{\circ}$ \\
\cline { 2 - 5 } & $\mathrm{CP}$ & $\mathrm{F} / \mathrm{CP}$ & 10 & $9.8 \pm 1.87^{\circ}$ \\
\cline { 2 - 5 } & $\mathrm{HP}+\mathrm{SA}$ & $\mathrm{F} / \mathrm{HP}+\mathrm{SA}$ & 10 & $13.5 \pm 2.48^{\mathrm{b}}$ \\
\cline { 2 - 5 } & $\mathrm{CP}+\mathrm{SA}$ & $\mathrm{F} / \mathrm{CP}+\mathrm{SA}$ & 10 & $13.5 \pm 2.42^{\mathrm{b}}$ \\
\hline
\end{tabular}

* The different letters indicate dissimilarity of groups $(p<0.05)$.

Table 3 - Failure modes of fractures.

\begin{tabular}{c|c|c|c|c}
\hline \multicolumn{2}{c|}{} & Adhesive & Cohesive & Mix \\
\hline \multirow{4}{*}{$\begin{array}{c}\text { Filtek } \\
\text { Supreme } \\
\text { XT }\end{array}$} & Control & $42.8 \%$ & $28.5 \%$ & $28.5 \%$ \\
\cline { 2 - 5 } & $\mathrm{F} / \mathrm{HP}$ & $92.8 \%$ & 0 & $7.1 \%$ \\
\cline { 2 - 5 } & $\mathrm{F} / \mathrm{HP}+\mathrm{SA}$ & $64.2 \%$ & $14.2 \%$ & $7.1 \%$ \\
\cline { 2 - 5 } & $\mathrm{F} / \mathrm{CP}$ & $85.7 \%$ & $7.1 \%$ & $7.1 \%$ \\
\cline { 2 - 5 } & $\mathrm{F} / \mathrm{CP}+\mathrm{SA}$ & $64.2 \%$ & $14.2 \%$ & $21.4 \%$ \\
\hline \multirow{4}{*}{$\begin{array}{c}\text { Filtek } \\
\text { Silorane }\end{array}$} & $\mathrm{Control}$ & $71.4 \%$ & $14.2 \%$ & $14.2 \%$ \\
\cline { 2 - 5 } & $\mathrm{S} / \mathrm{HP}$ & $92.8 \%$ & 0 & $7.1 \%$ \\
\cline { 2 - 5 } & $\mathrm{S} / \mathrm{HP}+\mathrm{SA}$ & $50 \%$ & $28.5 \%$ & $21.4 \%$ \\
\cline { 2 - 5 } & $\mathrm{S} / \mathrm{CP}$ & $57.1 \%$ & $28.5 \%$ & $14.2 \%$ \\
\cline { 2 - 5 } & $\mathrm{S} / \mathrm{CP}+\mathrm{SA}$ & $71.4 \%$ & $21.4 \%$ & $7.1 \%$ \\
\hline
\end{tabular}

were observed among the groups $\mathrm{F} / \mathrm{CP}+\mathrm{SA}(13.5$ $\mathrm{MPa}), \mathrm{F} / \mathrm{HP}+\mathrm{SA}(13.5 \mathrm{MPa}), \mathrm{F} / \mathrm{CP}(14.9 \mathrm{MPa})$, $\mathrm{S} / \mathrm{CP}+\mathrm{SA}(15.0 \mathrm{MPa}), \mathrm{S} / \mathrm{HP}+\mathrm{SA}(15.0 \mathrm{MPa})$, and S/CP (16.4 MPa). The latter groups demonstrated higher BS values than the former groups $(p<0.05)$. Table 3 shows the failure modes obtained with the MTBS test.

\section{Discussion}

We evaluated the effect of $10 \%$ SA treatment on the MTBSs of different composites to bovine enamel after vital bleaching procedures. The immediate application of SA solution increased the MTBS values in all groups. Therefore, the null hypothesis of this study was accepted.

In this study, a currently used silorane adhesive system was evaluated on flattened enamel. Lima et al. ${ }^{13}$ evaluated the influence of a bleaching treatment on the BS of DMA- and silorane-based composites to bovine enamel and found similar BS values for both restorative systems. Can-Karabulut and Karabulut $^{15}$ reported similar BS results for the Silorane Adhesive and Clearfil SE Bond systems in bleached and nonbleached enamel. Similarly, we observed no significant difference in terms of adhesive systems among the tested groups.

For vital bleaching treatments, oxygenating agents such as CP and HP are commonly used. ${ }^{16} \mathrm{HP}$ breaks down to water, oxygen ions, hydrogen ions, and free radicals. The diffused oxygen reacts with the stained molecules, which starts the bleaching process. ${ }^{17} \mathrm{CP}$ is used as a vehicle for transporting $\mathrm{H}_{2} \mathrm{O}_{2}$. First, CP breaks down to uric acid, ammonia, and $\mathrm{H}_{2} \mathrm{O}_{2}$, which forms $\mathrm{H}_{2} \mathrm{O}$ and $\mathrm{O}_{2}$. The oxygen takes electrons to bleach the enamel. ${ }^{16}$ Bleaching agents have been evaluated at different concentrations. In particular, $10 \%$ to $16 \% \mathrm{CP}$ and $30 \%$ to $36 \%$ HP have been preferred in many studies. ${ }^{18}$ In the present study, 35\% HP and 16\% CP were used.

The influences of HP and CP on enamel and dentin properties have been largely investigated. ${ }^{19}$ Due to the chemical properties of the bleaching agents, the mineral content of the dental hard tissue could change. ${ }^{20}$ Enamel bleaching immediately before bonding with adhesive systems might decrease the BS between materials. Thus, for BS to be established, restorative procedures are not recommended anywhere from 24 hours to 4 weeks after bleaching. ${ }^{21}$ To minimize the time that is required for restoration after bleaching, treatment with ascorbic acid can be preferred.

Ascorbic acid and its salt are well-known antioxidants that can reduce various oxidative compounds, especially free radicals. ${ }^{11}$ Kimyai and Valizadeh $^{10}$ found significantly higher BS values with DMA-based composites in SA-treated groups after $10 \%$ CP application. Freire et al. ${ }^{22}$ indicated that a $10 \%$ concentration of SA removed the residual peroxide up to 2 minutes after bleaching with $35 \% \mathrm{HP}$ and increased the bond strength of DMA-based 
composite resins to enamel. Silva et al. ${ }^{23}$ reported that bleached enamel without antioxidant application demonstrated the lowest BS values among the tested groups. Similarly, we found the highest BS values in the control and SA-treated groups, for both types of composite resin, when compared to the untreated groups. To our knowledge, no other study has examined the effect of SA on the BS of siloranebased composites after bleaching. The results of this study showed that SA application after bleaching treatment similarly increased the BS values of the silorane- and DMA-based composite groups.

Silorane-based composites have a different monomer structure (oxiranes and siloxanes) from traditional methacrylate chemistry, and they require a special adhesive system. This system includes a two-step self-etching procedure; etching procedures are not recommended. In particular, because it provided a similar application procedure, the Clearfil SE bond two-step self-etch adhesive system, which does not require an etching step, was used in this study. Lopes et al. ${ }^{24}$ reported that only the Clearfil SE bond system, which includes 10-methacryloxydecyl dihydrogen phosphate functional monomers in its composition, achieved a high enamel BS similar to that of etch-and-rise systems. This monomer has hydrolytic stability and forms additional chemical interac-

\section{References}

1. Mondell RFL, Azevedo JFDG, Francisconi AC, Almeida CM, Ishikirimama SK. Comparative clinical study of the effectiveness of different dental bleaching methods-two year follow up. J Appl Oral Sci. 2012 Jul-Aug;20(4):435-43.

2. Joiner A. Review of the effects of peroxide on enamel and dentin properties. J Dent. 2007 Dec;35(12):889-96.

3. Heymann O. Tooth whitening facts and fallacies. Br Dent J. 2005 Apr;198(8):5-14.

4. Garcia-Godoy F, Dodge WW, Donohue M, O'Quinn JA. Composite resin bond strength after enamel bleaching. Oper Dent.1993 Jul-Aug;18(4):144-7.

5. Titley KC, Torneck CD, Ruse ND, Krmec D. Adhesion of a resin composite to bleached and unbleached human enamel. J Endod. 1993 Mar;19(3):112-15.

6. Nikaido T, Takano Y, Sasafuchi Y, Burrow MF, Tagami J. Bond strengths to endodontically-treated teeth. Am J Dent. 1999 Aug;12(4):177-80. tions with dentin and enamel that contribute to its superior bonding. ${ }^{25}$ Therefore, in this study, an etching procedure was not considered necessary, due to the superior properties of the adhesive system.

Although using SA significantly increased the BS values after bleaching, the failure modes were mainly adhesive in all of the tested groups. Kahveci and Belli ${ }^{26}$ stated that higher BS values produce more cohesion and fewer adhesive failures. Phosphoric acid has been proven to produce deeper and more retentive microporosities than even the strongest selfetching adhesive. Thus, the ability of the etch-andrinse system to establish a valid micromechanical interlocking at the interface with enamel was also manifested by the higher frequency of cohesive failures. ${ }^{27}$ The use of self-etching adhesives on enamel in this study resulted in lower BS values and, consequently, mostly adhesive failures in all groups.

\section{Conclusions}

Within the limitations of the current study, we concluded that the application of $10 \%$ SA solution increased the MTBS values to enamel in all of the tested groups. After vital bleaching procedures, the immediate application of SA solution can be helpful for increasing the BS to enamel for both siloraneand DMA-based composites.

7. Rueggeberg FA, Margeson DH. The effect of oxygen inhibition on an unfilled/filled composite system. J Dent Res. 1990 Oct;69(10):1652-58.

8. Gökçe B, Cömlekoğlu ME, Ozpinar B, Türkün M, Kaya AD. Effect of antioxidant treatment on bond strength of a luting resin to bleached enamel. J Dent. 2008 Oct;36(10):780-85.

9. Lai SC, Mak YF, Cheung GS, Osorio R, Toledano M, Carvalho RM, et al. Reversal of compromised bonding to oxidized etched dentin. J Dent Res. 2001 Oct;80(10):1919-24.

10. Kimyai S, Valizadeh $H$. The effect of hydrogel and solution of sodium ascorbate on bond strength in bleached enamel. Oper Dent. 2006 Jul-Aug;31(4):496-9.

11. Buettner GR. The pecking order of free radicals and antioxidants: lipid peroxidation, alpha-tocopherol, and ascorbate. Arch Biochem Biophys.1993 Feb;300(2):535-43.

12. Türkün M, Kaya AD. Effect of $10 \%$ sodium ascorbate on the shear bond strength of composite resin to bleached bovine enamel. J Oral Rehabil. 2004 Dec;31(12):1184-91. 
13. Lima AF, Sasaki RT, Araújo LS, Gaglianone LA, Freitas MS, Aguiar FH, et al. Effect of tooth bleaching on bond strength of enamel-dentin cavities restored with silorane- and dimethacrylate-based materials. Oper Dent. 2011 Jul-Aug;36(4):390-6.

14. Mourouzis P, Koulaouzidou EA, Helvatjoglu-Antoniades M. Effect of in-office bleaching agents on physical properties of dental composite resins. Quintessence Int. 2013;44(4):295302.

15. Can-Karabulut D, Karabulut B. Influence of activated bleaching on various adhesive restorative systems. J Esthet Restore Dent. 2011 Dec;23(6):399-408.

16. Rosentritt M, Lang R, Plein T, Behr M, Handel G. Discoloration of restorative materials after bleaching application. Quintessence Int. 2005 Jan;36(1):33-9.

17. Haywood VB. History, safety and effectiveness of current bleaching techniques and applications of nightguard vital bleaching technique. Quintessence Int. 1992 Jul;23(7):471-88.

18. Danesh-Sani SA, Esmaili M. Effect of $10 \%$ sodium ascorbate hydrogel and delayed bonding on shear bond strength of composite resin and resin-modified glass ionomer to bleached enamel. J Conserv Dent. 2011 Jul;14(3):241-6.

19. Delfino CS, Chinelatti MA, Carrasco-Guerisoli LD, Batista AR, Fröner IC, Palma-Dibb RG. Effectiveness of home bleaching agents in discolored teeth and influence on enamel microhardness. J Appl Oral Sci. 2009 Jul-Aug;17(4):284-8.

20. Rodrigues JA, Oliveira GP, Amaral CM. Effect of thickener agents on dental enamel microhardness submitted to at-home bleaching. Braz Oral Res. 2007 Apr-Jun;21(2):170-5.
21. Barcellos DC, Benetti P, Fernandes Jr VV, Valera MC. Effect of carbamide peroxide bleaching gel concentration on the bond strength of dental substrates and resin composite. Oper Dent. 2010 Jul-Aug;35(4):463-9.

22. Freire A, Durski MT, Ingberman M, Nakao LS, Souza EM, Vieira S. Assessing the use of 35 percent sodium ascorbate for removal of residual hydrogen peroxide after in-office tooth bleaching. J Am Dent Assoc. 2011 Jul;142(7):836-41.

23. Silva AP, Lima AF, Cavalcanti AN, Marchi GM. Effects of $3 \%$ sodium ascorbyl phosphate on the hardness and bond strength of human enamel bleached with $10 \%$ carbamide peroxide. Gen Dent. 2010 Jul-Aug;58(4):174-8.

24. Lopes GC, Marson FC, Vieira LCC, de Andrada MAC, Baratieri LN. Composite bond strength to enamel with self-etching primers. Oper Dent. 2004 Jul-Aug;29(4):424-9.

25. Inoue S, Koshiro K, Yoshida Y, De Munck J, Nagakane K, Suzuki K, et al. Hydrolytic stability of self-etch adhesives bonded to dentin. J Dent Res. 2005 Dec;84(12): 1160-4.

26. Kahveci O, Belli S. Composite bond strength to intact enamel with current simplified adhesives. J Adhes Dent. 2011 Feb;13(1):31-7.

27. Beloica M, Goracci C, Carvalho CAR, Radovich I, Margvelashvili M, Vulicevic ZR, et al. Microtensile vs microshear bond strength of all-in-one adhesives to unground enamel. J Adhes Dent. 2010 Dec;12(6):427-33. 